\title{
Obtaining and characterizing dental hybrid composites with clay or silica nanoparticles and boron-aluminum-silicate glass microparticles
}

\author{
Lívia Rodrigues de Menezes ${ }^{1}$ and Emerson Oliveira da Silva ${ }^{\text {* }}$ \\ ${ }^{1}$ Instituto de Macromoléculas Professora Eloisa Mano, Universidade Federal do Rio de Janeiro - UFRJ, \\ Rio de Janeiro, RJ, Brasil \\ *eos@ima.ufrj.br
}

\begin{abstract}
The aim of the present work was the obtaining and characterization of dental hybrid composites using nanoparticles (clay or silica) and boron-aluminum-silicate microparticles. We evaluated the dispersion of the nanofillers when changing their loading among $2.5 \%, 5 \%, 10 \%$ and $25 \%$ wt. Were tested, in the above quantities, four different types of nanofillers, two nanosilicas and two nanoclays The remainder of the inorganic phase, up to a total loading of $75 \% \mathrm{wt}$, was given by the boron-aluminum-silicate microparticles. The systems were characterized by XRD, TGA, LF-NMR, and . FTIR was used to determine the degree of conversion. The XRD and LF-NMR showed that the composites with $2.5 \%$ of clays, contained an exfoliated profile, and the groups with higher amounts of clay showed intercalated areas or the agglomeration of these particles. Furthermore, the silicas were agglomerated in all groups. The thermal resistance of the material was not affected by the silicas, but improved when using $2.5 \%$ of nanoclays. On the other hand, the addition of these particles caused the reduction of the degree of conversion of the systems.
\end{abstract}

Keywords: acrylate matrixes, hybrid composites, organoclays, silicas.

How to cite: Menezes, L. R., \& Silva, E. O. (2019). Obtaining and characterizing dental hybrid composites with clay or silica nanoparticles and boron-aluminum-silicate glass microparticles. Polímeros: Ciência e Tecnologia, 29(2), e2019018. http://dx.doi.org/10.1590/0104-1428.01416

\section{Introduction}

The quality of dental restorative composites have been steadily increasing in recent years ${ }^{[1,2]}$. Dental composites usually consist of a polymer matrix with silanized filler and a photo-initiator system, with small amounts of photo-stabilizer and inhibitor, this composition represents a standard case of traditional design. The main monomers used in these materials are dimethacrylates, which include bisphenol A glycerolate dimethacrylate (BisGMA), triethylene glycol dimethacrylate (TEGDMA) and urethane dimethacrylate (UDMA) $)^{[1-3]}$.

Adjustment of the filler amount and size is very important with respect to composition because this affects the overall properties of these materials. The field of nanotechnology involves materials in the $1-100 \mathrm{~nm}$ size range, should be it has brought new practices and including the use of many nanofillers ${ }^{[4,5]}$. In dental composites, silica nanofillers, due to their high surface area and spherical form, cause a large increase in stiffness and decrease in roughness, however, the spherical and tiny shape leads to the formation of a high charge-charge interaction ${ }^{[6,7]}$, becoming more difficult to disperse than other fillers.

These materials require a high amounts of fillers for it to have a suitable viscosity to be sculpted. In this way the using of nanoparticles can cause difficulties of dispersion due to the high number of particles existing in a small mass of fillers and due their higher surface energy ${ }^{[8]}$, encouraging the obtaining of hybrid composites with a combination of micro and nanoparticles. In resin composites is very common the use of glass particles with high atomic numbers, such as barium, strontium, and zirconium ${ }^{[9]}$.

Clay-polymer systems can have many morphologies, which include: (1) agglomerated particles, where the layers remain joined and polymer chains only interact with the surface layers; (2) intercalated, when the polymer chain is intercalated between the host platelets; and (3) exfoliated, when the silicate platelets are isotropically dispersed in a continuous polymer matrix. The best enhancements in physical properties can be achieved with the exfoliated topology ${ }^{[10,11]}$.

Montmorillonite is a 2:1 phyllosilicate. Its crystalline structure consists of an aluminum hydroxide octahedral sheet sandwiched between two tetrahedral silicate layers ${ }^{[12]}$. Due to the organophilicity of the polymers, it is necessary to modify the clay surface with cationic surfactants such as alkylammonium or alkylphosphonium, forming the organoclay and providing expansion between the layers, facilitating the entry of the polymer chains within these. This is a key step to dispersion of these fillers in the polymer matrix ${ }^{[11]}$. In this way, these materials are of great interest in composite resin research, due to their reduced dimension, which increases 
the contact surface between matrix and fillers. In this field, nanoclay fillers are important and have been a subject of research in recent years due to the significant improvements small increments in these loadings can promote in the physicochemical properties of polymer composites ${ }^{[13,14]}$.

The aim of the present work was the obtaining and characterization of dental hybrid composites using montmorillonite clay and silica nanoparticles and boron-aluminum-silicate microparticles.

\section{Materials and Methods}

\subsection{Materials}

A standardized resin matrix was used containing a mixture of Bis-GMA, UDMA and TEGDMA in the proportion $35: 40: 25 \mathrm{wt} \%$ between them, associated with a camphorquinone (CQ) system-based as photoinitiator. We used as the nanofillers one of the following four types: two organically modified clays (Viscogel ${ }^{\circledR} \mathrm{B} 8$ and Dellite ${ }^{\circledR}$ $67 \mathrm{G}$ ), a hydrophilic silica (Aerosil ${ }^{\circledR} 200$ ) with $12 \mathrm{~nm}$ diameter, an organomodified silica (Aerosil ${ }^{\circledR}$ R972) with $16 \mathrm{~nm}$ diameter and a boron-aluminum-silicate glass with $4 \mu \mathrm{m}$ diameter. In the case of both clay their lamellas present a diameter between 100 and $200 \mathrm{~nm}$ and $1 \mathrm{~nm}$ thickness. In the all groups, the total filler loading was $75 \%$ wt. The nanofiller-only loading varied among $2.5 \%, 5 \%, 10 \%$ and $25 \% \mathrm{wt}$, the remainder $(72.5 \%, 70 \%, 65 \%, 50 \% \mathrm{wt}$, respectively) being the loading of microfillers.

All the mixtures were formulated to contain a standard loading of inorganic pigments based on metal oxide so that these experimental composites would match the $\mathrm{A} 3$ dentin color pattern on the Vita scale ${ }^{[15]}$. In all preparations, the matrix used belonged to the same production batch, thus avoiding possible changes in composition. The clays and hydrophobic silica were surface modified, while the hydrophilic silica had no modification. Both clays have been modified by Bis(Hydrogenated Tallow Alkyl) Dimethyl Ammonium. But Dellite ${ }^{\circledR} 67 \mathrm{G}$ has high content of modifier, and Viscoge ${ }^{\circledR}$ B8 has 10\% of 2-propanol. The hydrophobic silica, in turn, was modified by dimethyldichlorosilane (DDS). The surface modification of all fillers was maded by the manufacturer.

The use of microparticles was necessary for the dental resins because these materials are worked at very high filler loadings due to the need for to the resin to have high viscosity to enable modeling the restoration. This way, the presence of a mix with nano and microparticulated fillers in the dental resins led to obtaining hybrid composites.

\subsection{Methods}

The silicas and clay nanoparticles were combined with barium-alumino-silicate micrometer fillers glass $(\sim 4 \mu \mathrm{m})$. The proportion of filler/matrix was 75:25 wt/wt. Within the nanofiller, the load percentages were $2.5 \%, 5 \%, 10 \%$ and $25 \%$ in relation to the microfillers. The matrix/filler proportion was similar in all groups, with the only change being the relative amount of microfillers and nanoparticles. The filler and matrix were mixed by a FlackTek DAC 150 SpeedMixer ${ }^{\mathrm{TM}}$ (Landrum, SC, USA), according to the following method: initially the nanofillers of each group were added to the matrix, after which the systems were mixed in five cycles of five minutes each at increasing speeds of 1400, 1600, 2000, 2200 and $2400 \mathrm{rpm}$. Then, the microparticles were added to the mixture and subjected to the same mixing cycle, followed by two cycles of vacuum mixing (by manual rotation) for elimination of air bubbles that had been formed during mixing. The nanofillers were first added to the matrix in order to avoid high viscosity of the medium, which would hinder the dispersal of the particles.

\section{X-ray diffraction}

The exfoliation of nanoclay particles in resin and the crystallinity of silicas were analyzed by X-ray diffraction (XRD). The diffraction studies were performed with a Rigaku Ultima IV X-ray diffractometer (Tokyo, Japan) (CuK $\alpha$ irradiation, $40 \mathrm{kV}, 20 \mathrm{~mA}$ ) in the range of $2 \theta=1$ to $80^{\circ}$.

\section{Thermogravimetric analysis}

The thermogravimetric analysis (TGA) was performed on a Q50 thermobalance from TA Instruments, Inc. The samples with $15 \mathrm{mg}$ were heated from 30 to $700^{\circ} \mathrm{C}$, at a rate of $10^{\circ} \mathrm{C} / \mathrm{min}$, under nitrogen flow.

\section{Degree of conversion}

The degree of conversion (DC) of the systems was determined with Fourier transform infrared spectroscopy (FTIR: Spectrum 100 Optica; PerkinElmer, MA, USA), containing an attenuated total reflectance apparatus with a ZnSe crystal (Pike Technologies, Madison, WI, USA). The test was performed in the polymerized and unpolymerized samples and the DC was calculated using the band ratios of $1638 \mathrm{~cm}^{-1}$ and $1608 \mathrm{~cm}^{-1}$. The analysis was performed in 5 different samples from each group evaluated $(\mathrm{N}=5)$ in order to determine the statistical dispersions of the values.

\section{Low-field nuclear magnetic resonance}

To determine the relaxation measurements, a Maran Ultra low-field NMR (Resonance Instruments, Oxford, UK) was used, operating with the hydrogen nucleus at $23 \mathrm{MHz}$. Proton spin-lattice relaxation times were determined by inversion-recovery pulse sequence $\left(180^{\circ}-\tau-90^{\circ}\right)$ using 20 data points, with 4 scans for each and a range of $\tau$ varying from 0.1 to $5000 \mathrm{~ms}$, with $10 \mathrm{~s}$ of recycle delay and $90^{\circ}$ pulse of $4.5 \mu$ s, calibrated automatically by the instrument's software.

\section{Results}

The silicas characterization using X-ray diffraction (Figure 1) revealed an unorganized structure characterized by the presence of an amorphous halo centered at $2 \theta=22.35^{\circ}$ for the hydrophobic silica (Aerosi ${ }^{\circledR} \mathrm{R} 972$ ) and at $2 \theta=24.35^{\circ}$ for the hydrophilic silica (Aerosil ${ }^{\circledR} 200$ ) presented two diffraction peaks. The broad diffraction peaks from silicas indicate the predominantly amorphous structure.

The diffractograms of the clays exhibit the characteristic peaks of montmorillonite structures. The peak d001 of both clays are very close to $2 \theta=2^{\circ}$ indicating their already high interlamellar spacing due to the presence of the surface modifier. In the clays' diffractograms (Figure 2), the basal spacing was determined by applying Bragg's equation: $\mathrm{n} \lambda=2 \sin \theta$ to $\mathrm{d}(001)$ peak. The calculations showed that 
the basal spacing of the Dellite ${ }^{\circledR} 67 \mathrm{G}$ and Viscogel ${ }^{\circledR} \mathrm{B} 8$ are $31.6 \AA$ and $36.8 \AA$, respectively.

The composites diffractograms also revealed that the samples containing $5 \%-25 \%$ of both clays presented agglomerated systems because the peak $d(001)$ stayed in a similar position as the pure clay. On the other hand in groups containing $2.5 \%$ of both clays, the $\mathrm{d}(001)$ peak disappeared, this result can reflecting the exfoliation of the clays in these systems, or even an increase in spacing between platelets greater than the limit of diffractometer detection (44 $\AA$ ).

The initial degradation temperatures of all tested materials (Table 1) indicate that the silicas caused no significant changes in the thermal profile of the resins at any tested loadings, which may be related to the filler agglomeration. The clays, in turn, increased the thermal resistance of the material when used at $2.5 \%$ and reduced this resistance at the other loadings tested. This behavior indicates that the less concentrated group presents better particle dispersion and the other clay loadings caused a more crowded profile.

From analysis of Low Field Nuclear Magnetic Resonance (LF-NMR), the longitudinal relaxation time of hydrogen $\left(\mathrm{T}_{1} \mathrm{H}\right)$ values (Table 2 ) indicate that the Viscogel ${ }^{\circledR} 67 \mathrm{G}$ and Dellite ${ }^{\circledR} \mathrm{B} 8$, when added to the system at a loading of $2.5 \%$, caused a significant decrease in the spin-relaxation time of the hydrogen nucleus network, proving the formation of a composite with a high degree of exfoliation. The silicas, in turn, caused no significant change in the relaxation times compared with the control group ( $0 \%$ of nanofillers).

The results of DC obtained from the FTIR spectra (Table 3), showed that the degree of conversion of the evaluated resins comprised between $40.72 \%$ and $27.38 \%$. As well it showed that the increase of nanoparticles in the system caused the reduction of the degree of conversion of these systems.
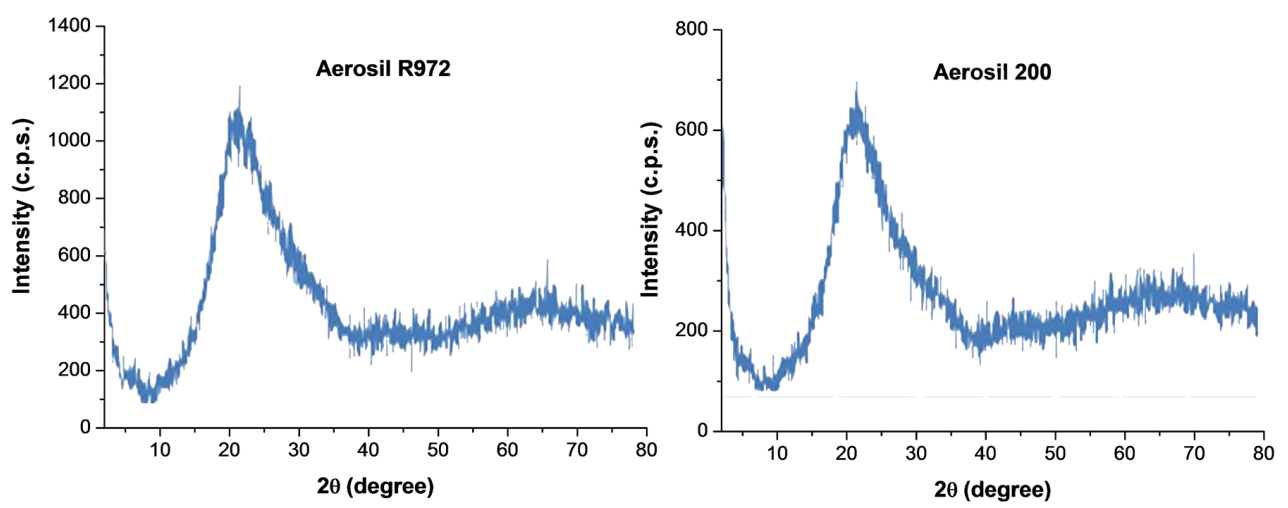

Figure 1. XRD patterns of (a) Aerosil ${ }^{\circledR}$ R972 and (b) Aerosil ${ }^{\circledR} 200$.
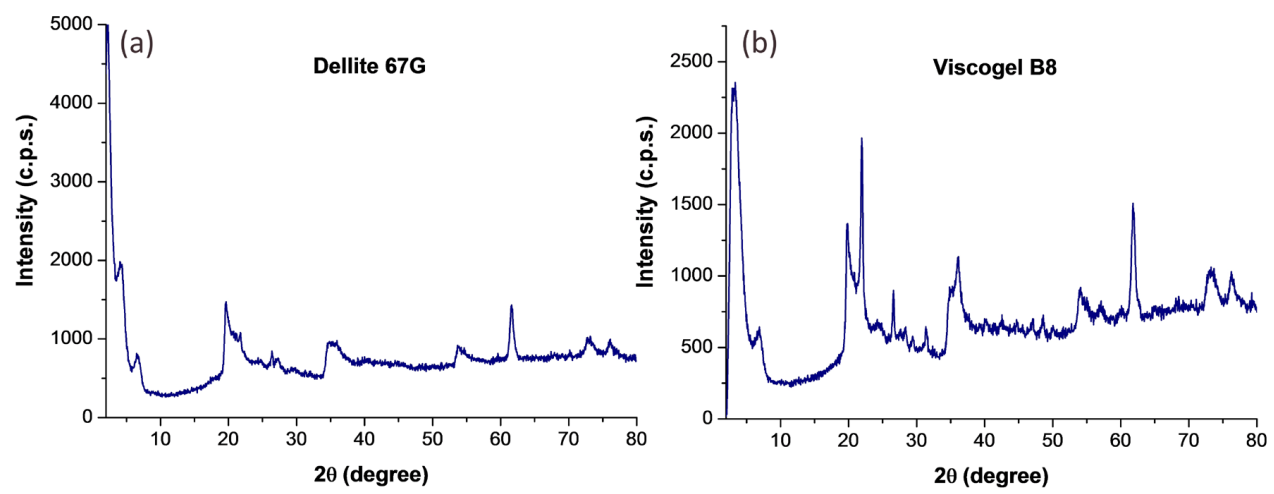

Figure 2. XRD patterns of nanoclays (a) Dellite ${ }^{\circledR} 67 \mathrm{G}$ (b) Viscogel ${ }^{\circledR}$ B8.

Table 1. Initial degradation temperatures of all tested materials.

\begin{tabular}{lccccc}
\hline \multirow{2}{*}{ Filler } & \multicolumn{5}{c}{ Initial degradation temperature $\left({ }^{\circ} \mathbf{C}\right)$} \\
\cline { 2 - 6 } & $\mathbf{0 \%}$ & $\mathbf{2 . 5 \%}$ & $\mathbf{5 \%}$ & $\mathbf{1 0 \%}$ & $\mathbf{2 5 \%}$ \\
\hline Dellite $^{\circledR}$ 67G & 369 & 379 & 351 & 333 & 332 \\
Viscogel $^{\circledast}$ B8 & 369 & 377 & 362 & 346 & 343 \\
Aerosi $^{\circledast}$ 200 & 369 & 369 & 364 & 369 & 367 \\
Aerosil $^{\circledR}$ R972 & 369 & 366 & 370 & 367 & 369 \\
\hline
\end{tabular}


Menezes, L. R., \& Silva, E. O.

Table 2. TH values of all tested materials.

\begin{tabular}{lccccc}
\hline \multirow{2}{*}{ Filler } & \multicolumn{5}{c}{ T $_{\mathbf{1}}$ H values (ms) } \\
\cline { 2 - 6 } & $\mathbf{0 \%}$ & $\mathbf{2 . 5 \%}$ & $\mathbf{5 \%}$ & $\mathbf{1 0 \%}$ & $\mathbf{2 5 \%}$ \\
\hline Dellite $^{\circledR}$ 67G & 62 & 15 & 45 & 42 & 45 \\
Viscogel $^{\circledR}$ B8 & 62 & 15 & 42 & 46 & 54 \\
Aerosi $^{\circledR}$ 200 & 62 & 60 & 63 & 61 & 61 \\
Aerosi $^{\circledR}$ R972 & 62 & 59 & 59 & 62 & 60 \\
\hline
\end{tabular}

Table 3. Degree of conversion of all tested materials.

\begin{tabular}{|c|c|c|c|c|c|}
\hline \multirow{2}{*}{ Filler } & \multicolumn{5}{|c|}{ Degree of Conversion } \\
\hline & $0 \%$ & $2.5 \%$ & $5 \%$ & $10 \%$ & $25 \%$ \\
\hline Dellite $^{\circledR} 67 \mathrm{G}$ & $44 \pm 3 \mathrm{~A}$ & $38 \pm 3 \mathrm{~B}$ & $31 \pm 2 \mathrm{C}$ & $29 \pm 3 \mathrm{CD}$ & $28 \pm 2 \mathrm{D}$ \\
\hline Viscogel ${ }^{\circledR} \mathrm{B} 8$ & $44 \pm 3 \mathrm{~A}$ & $41 \pm 3 \mathrm{AB}$ & $34 \pm 2 \mathrm{C}$ & $32 \pm 2 \mathrm{C}$ & $27 \pm 3 \mathrm{D}$ \\
\hline Aerosil $^{\circledR} 200$ & $44 \pm 3 \mathrm{~A}$ & $37 \pm 2 \mathrm{~B}$ & $38 \pm 3 \mathrm{~B}$ & $31 \pm 1 \mathrm{C}$ & $29 \pm 3 \mathrm{CD}$ \\
\hline Aerosil ${ }^{\circledR}$ R972 & $44 \pm 3 \mathrm{~A}$ & $41 \pm 4 \mathrm{AB}$ & $39 \pm 2 \mathrm{~B}$ & $39 \pm 3 \mathrm{~B}$ & $33 \pm 1 \mathrm{C}$ \\
\hline
\end{tabular}

Means followed by different letters differ from each other by Tukey Test $(\mathrm{p} \leq 0.05)$.

\section{Discussion}

The diffractograms of the resins with both clays (Figure 3) revealed the absence of exfoliation in groups containing $5 \%$, $10 \%$ and $25 \%$ of these fillers. In the group with $2.5 \%$, there was no peak $\mathrm{d}(001)$. This can be interpreted as reflecting an increase in the interlayer spacing to over $44 \AA$, being beyond the detection limit of the equipment. In this case, the system can be intercalated or exfoliated, requiring another technique to evaluate its configuration.

The dispersion of silicas can not be determined by XRD analysis becase these fillers have spherical shape, because of these the silicas dispersion was determined by NMR analysis. Based on the XRD results, it can be determined that the increase in clay loading led to a decrease in the dispersibility of these fillers, this behavior has been reported in previous studies ${ }^{[16,17]}$. This lower dispersion of clay is the cause of the increase in viscosity of these nanofillers, rather than their bare increase of loading. Another possibility relates to the increase of the number of particles in the system that generates a physical impediment to their dispersion, since there is limited space for a greater possibility of reunion and consequent agglomeration of these particles in more concentrated systems ${ }^{[16,17]}$.

The change observed in the groups with nanoclays is due to the type of distribution of these particles in the system. The increased temperature required for weight loss in the groups with lower clay loadings indicates that this system is exfoliated, corroborating the diffraction results. Similar studies have shown that this behavior results when these fillers are exfoliated. This fact can be attributed to the ability of layered structures to reduce the flow of gases within the material, and in this way, the heat flow ${ }^{[18,19]}$. In the other groups, in turn, there was a reduction in the mass loss temperature, which probably occurred because of the degradation of organic modifier present in these minerals, something that occurs when these fillers are agglomerated in a polymer system ${ }^{[20,21]}$.

Thus, the LF-NMR analysis is in agreement with the results obtained by $\mathrm{XRD}$, since the relaxation times also show a possible exfoliated profile in mixtures containing $2.5 \%$ clay and the absence this at other loadings of these fillers. Similarly, the XRD showed that with loadings of 5\% and $10 \%$, secondary peaks appeared at angles smaller than the basal peaks. This finding, combined with the relaxation time reduction, confirms the presence of part of these fillers in the intercalated topology.

The reduction of relaxation times in the exfoliated configuration occurs because the clays used in the experiment were members of groups of montmorillonites characterized by high iron loadings. This compound causes a resonance effect, called a paramagnetic effect, which causes a change of the magnetic field reducing the relaxation periods of hydrogen nuclei of the polymer chains around the particles. Thus, exfoliated systems, because of their better dispersion, have more polymer chains under the influence of the paramagnetic effect. This causes a decrease in relaxation time, which is observed by LF-NMR ${ }^{[22,23]}$.

The explanations of this phenomenon are based on the presence of polymer chains around the clay layers, which brings the hydrogen nuclei of the paramagnetic metals that make up the clay layers nearer together. These metals act as relaxation agents, causing a decrease in the $\mathrm{T}_{1} \mathrm{H}$ interval ${ }^{[22,23]}$. In silica groups, the interaction between fillers and matrix reduces the mobility of the chains ${ }^{[24]}$. Thus, a decrease in relaxation time can be expected. However, as previously noted, these fillers are agglomerated in the system. The cluster formation decreases the interaction between the nanoparticles and matrix, thus reducing the effect on relaxation time.

The results showed that addition of nanoparticles lead to reduction of DC for the evaluated systems. This behavior has been previously reported in other studies with different nanoparticles. The reduction of polymerization conversion in these cases stems from the increase in viscosity of the system $^{[25]}$, which hinders the movement of its constituent during the polymerization, as well as, by the interaction of the nanoparticles with the light that can act as agents of the absorption and scattering of light, making the photoinitiation process less effective ${ }^{[26]}$. 

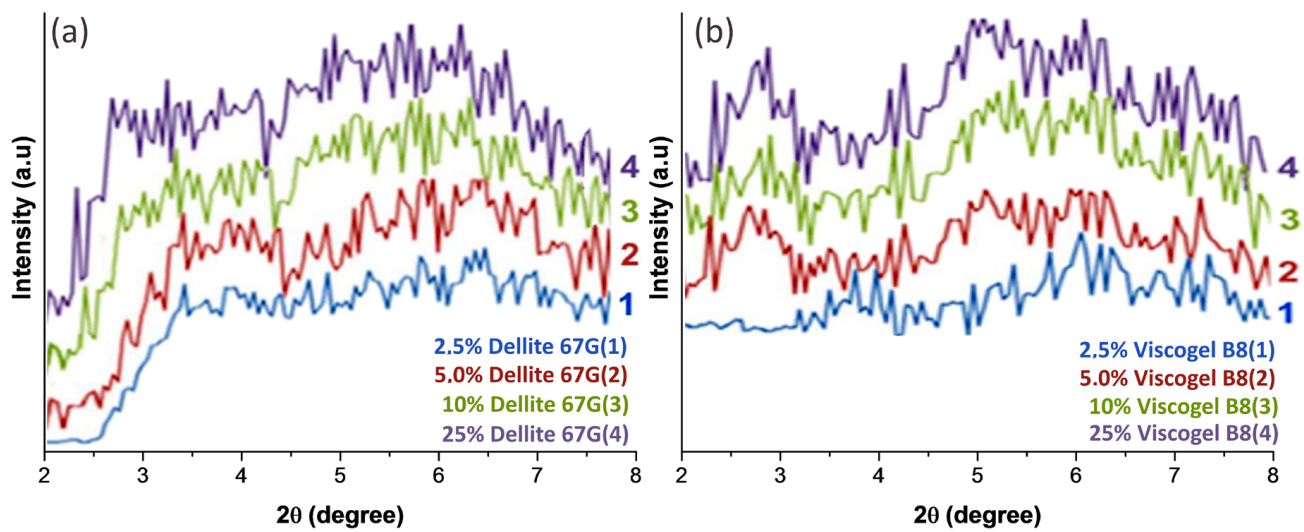

Figure 3. XRD patterns of (a) composites with nanoclay Dellite ${ }^{\circledR} 67 \mathrm{G}$, (b) composites with nanoclay Viscogel ${ }^{\circledR}$ B8.

\section{Conclusions}

Based on the results, it can be concluded that:

- The groups with organoclay loading of $2.5 \%$ produced exfoliated material, a fact proven by the findings of the XRD and LF- NMR techniques;

- The clay fillers, when their loading was increased up to $5 \%$ and $10 \%$, resulted into hybrid systems (partially exfoliated, partially agglomerated) and the groups with higher amounts of these fillers showed an agglomerated profile;

- All the groups containing silicas (hydrophobic and hydrophilic), were agglomerated and shows a poor dispersion when compared to the clays;

- The thermal resistance of the material was not affected by the fillers of Aerosil ${ }^{\circledR} 200$ and Aerosil ${ }^{\circledR}$ R972, but improved when using 2.5\% Dellite ${ }^{\circledR} 67 \mathrm{G}$ and $2.5 \%$ Viscogel ${ }^{\circledR} \mathrm{B} 8$ and reduced with the addition of particles in the latter two groups of $5 \%, 10 \%$ and $25 \%$;

- As the nanoparticles are added in the systems there is a gradual reduction of the composite DC indicating that the presence of these damages the polymerization process of the dental resins.

\section{Acknowledgements}

Authors thanks Coordenação de Aperfeiçoamento de Pessoal de Nível Superior - CAPES, Conselho Nacional de Desenvolvimento Científico e Tecnológico - CNPq and Fundação de Amparo à Pesquisa do Estado do Rio de Janeiro - FAPERJ for financial support.

\section{References}

1. Ferracane, J. L. (2011). Resin composite-state of the art. Dental Materials, 27(1), 29-38. http://dx.doi.org/10.1016/j. dental.2010.10.020. PMid:21093034.

2. Chen, M. H. (2010). Update on dental nanocomposites. Journal of Dental Research, 89(6), 549-560. http://dx.doi. org/10.1177/0022034510363765. PMid:20299523.
3. Hosseinalipour, M., Javadpour, J., Rezaie, H., Dadras, T., \& Hayati, A. N. (2010). Investigation of mechanical properties of experimental Bis-GMA/TEGDMA dental composite resins containing various mass fractions of silica nanoparticles. Journal of Prosthodontics, 19(2), 112-117. http://dx.doi. org/10.1111/j.1532-849X.2009.00530.x. PMid:19895426.

4. Uskoković, V., \& Bertassoni, L. E. (2010). Nanotechnology in dental sciences: moving towards a finer way of doing dentistry. Materials (Basel), 3(3), 1674-1691. http://dx.doi.org/10.3390/ ma3031674. PMid:27103959.

5. Salerno, M., \& Diaspro, A. (2015). Dentistry on the bridge to nanoscience and nanotechnology. Frontiers in Materials, 2, 19. http://dx.doi.org/10.3389/fmats.2015.00019.

6. Rastelli, A. N. S., Jacomassi, D. P., Faloni, A. P. S., Queiroz, T. P., Rojas, S. S., Bernardi, M. I. B., Bagnato, V. S., \& Hernandes, A. C. (2012). The filler content of the dental composite resins and their influence on different properties. Microscopy Research and Technique, 75(6), 758-765. http:// dx.doi.org/10.1002/jemt.21122. PMid:22213178.

7. Marghalani, H. Y. (2010). Effect of filler particles on surface roughness of experimental composite series. Journal of Applied Oral Science, 18(1), 59-67. http://dx.doi.org/10.1590/S167877572010000100011. PMid:20379683.

8. Uhm, Y. R., Kim, J., Lee, S., Jeon, J., \& Rhee, C. K. (2011). In situ fabrication of surface modified lead monoxide nanopowder and its HDPE nanocomposite. Industrial \& Engineering Chemistry Research, 50(8), 4478-4483. http:// dx.doi.org/10.1021/ie102300x.

9. Ermis, R. B., Yildirim, D., Yildiz, G., \& Gormez, O. (2014). Radiopacity evaluation of contemporary resin composites by digitization of images. European Journal of Dentistry, 8(3), 342-347. http://dx.doi.org/10.4103/1305-7456.137644. PMid:25202214.

10. Sinha Ray, S., \& Okamoto, M. (2003). Polymer/layered silicate nanocomposites: a review from preparation to processing. Progress in Polymer Science, 28(11), 1539-1641. http://dx.doi. org/10.1016/j.progpolymsci.2003.08.002.

11. Ruiz-Hitzky, E., \& Van Meerbeek, A. (2006). Clay mineral and organoclay-polymer nanocomposite. In F. Bergaya, B. K. G. Theng \& G. Lagali (Eds.), Handbook of clay science, developments in clay science 1 (pp. 583-621). Amsterdam: Elsevier. http://dx.doi.org/10.1016/S1572-4352(05)01018-4.

12. Paiva, L. D., Morales, A. R., \& Díaz, F. R. V. (2008). Argilas organofílicas: características, metodologias de preparação, 
compostos de intercalação e técnicas de caracterização. Cerâmica, 54(330), 213-226. http://dx.doi.org/10.1590/S036669132008000200012.

13. Manias, E., Touny, A., Wu, L., Strawhecker, K., Lu, B., \& Chung, T. C. (2001). Polypropylene/montmorillonite nanocomposites. Review of the synthetic routes and materials properties. Chemistry of Materials, 13(10), 3516-3523. http:// dx.doi.org/10.1021/cm0110627.

14. Alexandre, M., \& Dubois, P. (2000). Polymer-layered silicate nanocomposites: preparation, properties and use of a new class of materials. Materials Science and Engineering R Reports, 28(12), 61-68. http://dx.doi.org/10.1016/S0927-796X(00)00012-7.

15. Hassel, A. J., Zenthöfer, A., Corcodel, N., Hildenbrandt, A., Reinelt, G., \& Wiesberg, S. (2012). Determination of VITA classical shades with the 3D-Master shade guide. Acta Odontologica Scandinavica, 71(3-4), 721-726. http://dx.doi. org/10.3109/00016357.2012. PMid:23146130.

16. Sadat-Shojai, M., Atai, M., Nodehi, A., \& Khanlar, L. N. (2010). Hydroxyapatite nanorods as novel fillers for improving the properties of dental adhesives: synthesis and application. Dental Materials, 26(5), 471-482. http://dx.doi.org/10.1016/j. dental.2010.01.005. PMid:20153516.

17. Saif, M. J., \& Asif, H. M. (2015). Escalating applications of halloysite nanotubes. Journal of the Chilean Chemical Society, 60(2), 2949-2953. http://dx.doi.org/10.4067/S071797072015000200019.

18. Zhou, Q., \& Xanthos, M. (2009). Nanosize and microsize clay effects on the kinetics of the thermal degradation of polylactides. Polymer Degradation \& Stability, 94(3), 327-338. http://dx.doi.org/10.1016/j.polymdegradstab.2008.12.009.

19. Feng, J., Hao, J., Du, J., \& Yang, R. (2012). Using TGA/ FTIR TGA/MS and cone calorimetry to understand thermal degradation and flame retardancy mechanism of polycarbonate filled with solid bisphenol A bis (diphenyl phosphate) and montmorillonite. Polymer Degradation \& Stability, 97(4), 605 614. http://dx.doi.org/10.1016/j.polymdegradstab.2012.01.011.

20. Kashiwagi, T., Morgan, A. B., Antonucci, J. M., VanLandingham, M. R., Harris, R. H., Awad, W. H., \& Shields, J. R. (2003).
Thermal and flammability properties of a silica-poly (methylmethacrylate) nanocomposite. Journal of Applied Polymer Science, 89(8), 2072-2078. http://dx.doi.org/10.1002/ app. 12307.

21. Tian, Y., Yu, H., Wu, S., Ji, G., \& Shen, J. (2004). Study the structure and properties of EVA/clay nanocomposites. Journal of Materials Science, 39(13), 4301-4303. http://dx.doi. org/10.1023/B:JMSC.0000033412.92494.ee.

22. Tavares, M. I. B., Nogueira, R. F., Gil, R. A. S., Preto, M., Silva, E. O., Silva, M. B. R., \& Miguez, E. (2007). Polypropyleneclay nanocomposite structure probed by H NMR relaxometry. Polymer Testing, 26(8), 1100-1102. http://dx.doi.org/10.1016/j. polymertesting.2007.07.012.

23. Silva, M. A., Tavares, M. I. B., Nascimento, S. A., \& Rodrigues, E. J. D. R. (2012). Caracterização de nanocompósitos de poliuretano/montmorilonita organofílica por RMN de baixo campo. Polímeros: Ciência e Tecnologia, 22(5), 481-485. http://dx.doi.org/10.1590/S0104-14282012005000064.

24. Passos, A. A., Tavares, M. I. B., Neto, R. C. P. \& Ferreira. A. G. (2012). The use of solid state NMR TO evaluate EVA/silica films. Journal of Nano Research, 18-19, 219-226. http://dx.doi.org/10.4028/www.scientific.net/ JNanoR. 18-19.219.

25. Leprince, J. G., Palin, W. M., Hadis, M. A., Devaux, J., \& Leloup, G. (2013). Progress in dimethacrylate-based dental composite technology and curing efficiency. Dental Materials, 29(2), 139-156. http://dx.doi.org/10.1016/j.dental.2012.11.005. PMid:23199807.

26. Carreno, N. L. V., Oliveira, T. C. S., Piva, E., Leal, F. B., Lima, G. S., Monks, M. D., Raubach, C. W., \& Ogliari, F. A. (2012). YbF 3 / SiO 2 Fillers as Radiopacifiers in a Dental Adhesive Resin. Nano-Micro Letters, 4(3), 189-196. http:// dx.doi.org/10.1007/BF03353713.

Received: Feb. 22, 2016 Revised: May 31, 2017 Accepted: June 01, 2017 